\title{
Robust product design and process planning in using process capability analysis
}

\author{
Angus Jeang
}

Received: 2 October 2012 / Accepted: 4 June 2013 / Published online: 25 June 2013

(C) The Author(s) 2013. This article is published with open access at Springerlink.com

\begin{abstract}
In the past, the process capability index (PCI) was the only method used in on-line quality management. Recently however, attempts have been made to extend the on-line application to off-line applications, such as product design or process planning. Because the conventional PCI index, $C_{p m}$, does not truly represent the measurement score, alternatives cannot be differentiated during off-line applications. Hence, a new process capability index, $C_{p m c}$, was developed to reflect the differences among alternatives for easy decision making at the product design and process planning stages; however, the deterministic approach in using this new process capability index has the disadvantage of dealing with uncertainties during the product design and process planning activities. Quality engineering often employs an effective way of ensuring that high product quality and low production cost result from robust design, particularly in terms of its application in an uncertain environment. The new PCI was the score mainly used for off-line applications; thus, there is motivation for using new PCI values, $C_{p m c}$, as the observed levels in the course of robust design implementation. The associated statistical method, response surface methodology, will be adopted for robust design in this study. Then, for robustness, the mean and tolerance values can be determined appropriately, as well as a measurement score for reasonable comparison and selection among candidates. Consequently, an economical and quality product design and process planning can be achieved statistically for the off-line applications.
\end{abstract}

Keywords Process capability index (PCI) - Mean · Tolerance $\cdot$ Off-line application $\cdot$ Robustness $\cdot$ RSM

A. Jeang $(\varangle)$

Department of Industrial Engineering and Systems Management, Feng Chia University, P.O. Box 25-150, Taichung, Taiwan, ROC e-mail: akjeang@fcu.edu.tw

\section{Introduction}

Since the manufacturing industry is currently facing intensive competition, both cost and quality have become important concerns of management. Thus, producers strive to provide economical processes which are also capable of meeting customers' quality requirement. In recent years, as the concept of concurrent engineering has become widely accepted, design engineers have hoped to achieve simultaneous product design and process planning, side by side, at an early stage of product development (Carter and Baker 1992; Bare and Cox 2008; Marshall and Jordan 2008; Michel et al. 2010; Mohsen et al. 2010). The goals are to shorten the time span required for introducing the new product onto the market, while attaining the lowest production cost coupled with premium product quality. Hence, what is needed is a way to measure the degree to which the producer's process capability satisfies customers' quality requirement. More importantly, a growing number of producers include this measurement value in their purchase contracts with customers, as a documentation requirement. One such measurement is the process capability index (PCI).

The PCI is a value that reflects real-time quality status. The PCI acts as a reference for real-time monitoring; it enables process controllers to acquire a better grasp of the quality of on site processes (Kotz and Johnson 1993; Kotz and Lovelace 1998). Although the PCI is one of the quality measurements employed during on-line quality management, several authors have pointed out that the PCI should be addressed at the beginning of the design stage rather than at the production stage, where process capability analysis is typically done. Thus, Jeang recently developed a PCI expression, $C_{p m c}$, extended from $C_{p m}$ for an off-line application (Jeang and Chung 2009; Jeang 2009). 
The statistical approach combines robust design with experimental design methods (Hussain et al. 2011). The purpose of the statistical approach is to determine which components significantly affect the quality, functionality and cost of a product or manufacturing process. One of the experimental design methods, RSM, is adopted for analyzing the measurement scores, the process capability index $\left(C_{p k}\right)$ (Lee et al. 2010). To continue examining robust design with process capability index, $C_{p m c}$ values are used for process planning and product design in this study. RSM is an effective method of exploring the relationship between controllable variables and response values, and indicates the critical controllable variables, while mathematically searching for the optimal values and statistically analyzing problems (Montgomery 1991). Another important feature of RSM is that it requires fewer experimental runs than the factorial design of experiments (DOEs) as attested in the literature. In this study, a Box-Behnken Design (BBD) was used because it allows the efficient estimation of the first and second order coefficients of regression functions.

This paper is organized as follows: Sect. 1 presents the introduction, Sects. 2 and 3 contain information relevant to the background. Section 2 discusses why the statistical design via statistical method is necessary for uncertain environments. Section 3 introduces the statistical method, RSM, which is adopted in this research. Section 4 introduces the new PCI which will be used for statistical analysis. Section 5 provides an application showing the proposed approach. Finally, a summary is given in Sect. 6.

\section{Robust design for uncertainty}

There are a few shortcomings in a design that uses the deterministic approach. Models that represent the interaction between the variables and their relationship to the end product's performance are virtually unknown. Conventionally, the approach in determining quality values (design values) of controllable variables according to the expected product performance is often an iterative process. Namely, it is possible to go back and assign new component design values to produce different product performance until a satisfactory yield has been achieved. The trial used in assigning new quality value (design value) of the controllable variable is inefficient because of possible dependence among various controllable variables. In addition, the approach cannot suggest which component is important and what the exact variable quality values should be, particularly when dependence is present. Hence, moving trials forward and backward becomes a very time consuming and tedious task; it slows down the pace of product development. Moreover, designers prefer to have as many feasible designs as possible in order to allow for changes when they encounter complexities. This tendency makes the above discussions even more problematic. For design activities, besides optimal solutions, a statistical view of the analysis of the design problem is also necessary, particularly under uncertain design conditions (Jeang and Chang 2002). Quality engineering often employs the statistical method for robust design; it improves product or process quality by reducing the effects of variation in order to facilitate product functionality (Phadke 1989; Taguchi and Wu 1985; Du et al. 2012; Sibalija and Majstorovic 2012). The effectiveness of robust design can be achieved by using a statistical method such as DOE (Montgomery 1991). Usually, product or process engineers utilize DOE to reduce the effects of variation by suggesting a proper direction for design or process improvements. The purpose of the DOE is to determine which of the design variables significantly affect the response values. This feature, in determining critical design variables, is very important, particularly when new products or processes are developed. The statistical method, response surface methodology (RSM), will be adopted in this study (Montgomery 1991).

\section{Experimental designs with RSM}

Usually, the relationship between the dependent variable and the independent variable is extremely complex or unknown; however, RSM provides a procedure that solves this problem (Montgomery 1991). Assume that the designer is concerned with a system involving some response values $\mathrm{R}$, which depend on input variables $X_{i}$. For convenience, these input variables are also called design variables in later discussion. It is also assumed that $X_{i}$ is continuous and controllable. The functional relationship between the response and the levels of $n$ inputs can be written as:

$R=f\left(X_{1}, X_{2}, \ldots, X_{n}\right)$

This determines whether a mechanistic model for such a relationship exists. Thus, the first step in RSM is to find a suitable approximation for $f($.) using a low-order polynomial in some region of the independent variables. If the approximated function has linear variables, a first-order polynomial can be used and written in terms of the design variables:

$R=a_{0}+a_{1} X_{1}+a_{2} X_{2}+\cdots+a_{n} X_{n}$

Otherwise, a second-order polynomial can be used:

$R=a_{0}+\sum_{i=1}^{n} a_{i} X_{i}+\sum_{i=1}^{n} b_{i} X_{i}^{2}+\sum_{i=1}^{n} \sum_{j=1}^{n} c_{i j} X_{i} X_{j}$

The frequent use of second-order polynomial models is justified by the fact that they reflect the nonlinear behavior of the system. Experimental designs for fitting a second-order response surface must involve at least three levels of each 
variable so that the coefficients in the model can be estimated. A rotability property is desirable for response surface models because the orientation of the design with respect to its surface is unknown. This study uses a Box-Behnken design because it allows efficient estimation of the first and second order coefficients. Using this experimental design, the levels of each input factor are assumed to be equally spaced. A least squares estimate is used to estimate the coefficients in approximating the polynomials. The response surface analysis then proceeds in terms of the fitted surface. If the fitted surface is an adequate estimation of the true functional relationship, then the analysis of the fitted response will be nearly equivalent to the analysis of the studied problem.

\section{Process capability index as response values for statistical analysis}

The PCI expression in Eq. (4), $C_{p m}$, is able to simultaneously reflect the influences of process deviation and process variance (Boyle 1991; Chan et al. 1989). This is only legitimate at the post-production stage due to the fact that $U$ and $t$ are realized values which are not controllable for design:

$C_{p m}=\frac{U S L-L S L}{6 \sqrt{K\left[\sigma^{2}+(U-T)^{2}\right]}}$

$U S L$ and $L S L$ are the upper and lower limits, respectively. However, when $C_{p m}$ is used as a measurement scale in the pre-production stage under the assumption that $\sigma$ is $t / P, U$ and $t$ become controllable variables. Then, it is possible that various combinations of $U$ and $t$ will result in the same $C_{p m}$ value. Thus, it is difficult to make a distinction among alternatives in seeking to make a correct choice from among them. For example, the curve shown in Fig. 1 represents all possible combinations of $U$ and $t$ which have $C_{p m}$ as 1.2 without differentiation.

Additionally, when $C_{p m}$ is used as a measurement scale in the pre-production stage, the designers would most likely establish the process mean $U$ as close as possible to the design $\operatorname{target} T$, within the process feasibility range, and attempt to decrease the process variance as much as possible, within the process capability limits, in order to attain a higher PCI value. It is known that cutting down process variance with small process tolerance $t$ normally results in high tolerance cost (production cost). In other words, with the exclusive use of the process mean and process variance as the determinants of conventional PCI, $C_{p m}$, regardless of the cost impact on customer and production, there is a tendency for designers to position the process mean as close to the target value $T$ as possible, and cut down the process tolerance to lower capability limit in order to increase the PCI value. Apparently, the found PCI value is erroneous. This unhelpful result will

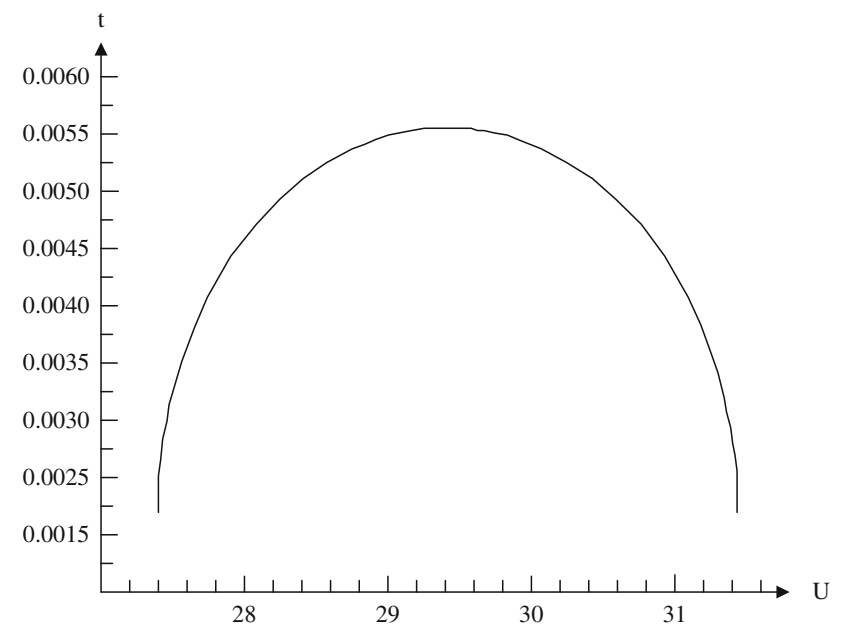

Fig. 1 Feasible range for various combination of $U$ and $t$ with $T=30$, $L S L=29.95, U S L=30.05, \sigma=t / P, P=3$, when $C_{p m}=1.2$

prevent the conventional $C_{p m}$ from being a suitable index for possible alternatives during product design or process planning.

To overcome the above weaknesses, the lack of considering cost influence on deviation and variability should be avoided. It is known that the cost in representing the magnitude of deviation and variability is formed as a function of controllable variables, which contain process mean $U$ and process tolerance $t$. In this regard, a new PCI expression is developed by having the non-cost expression $E(X)$, like Eq. (5), replaced with the quality and production related cost expression $\mathrm{C}(X)$ as Eq. (6):

$$
\begin{aligned}
& E(X)=\sigma^{2}+(U-T)^{2} \\
& C(X)=K\left[\sigma^{2}+(U-T)^{2}\right]+C_{M}(t)
\end{aligned}
$$

The first term of Eq. (6) is "quality related cost" which is also referred to as "loss function" (Phadke 1989; Taguchi and Wu 1985). The second term of Eq. (6) is "production related cost" which is also called "tolerance cost function" (Chase et al. 1990). These two terms are needed to balance economical and quality considerations. They are depicted in Figs. 2 and 3 correspondingly. A narrower $\sigma^{2}$ can result in small quality related cost; however, the narrower one may lead to a greater production cost because of contracted tolerance $t$. Thus, we usually try to locate process mean $U$ as close to design target $T$ as possible before involving competitive process variance $\sigma^{2}$ and process tolerance $t$.

The sum of two cost terms is the total cost representing the quality level of a product or process (Jeang 1994). Consequently, the cost effectiveness and quality achievement PCI score becomes capable of evaluating and distinguishing alternative product designs or process planning. This PCI expression, $C_{p m c}$, is shown as follows: 


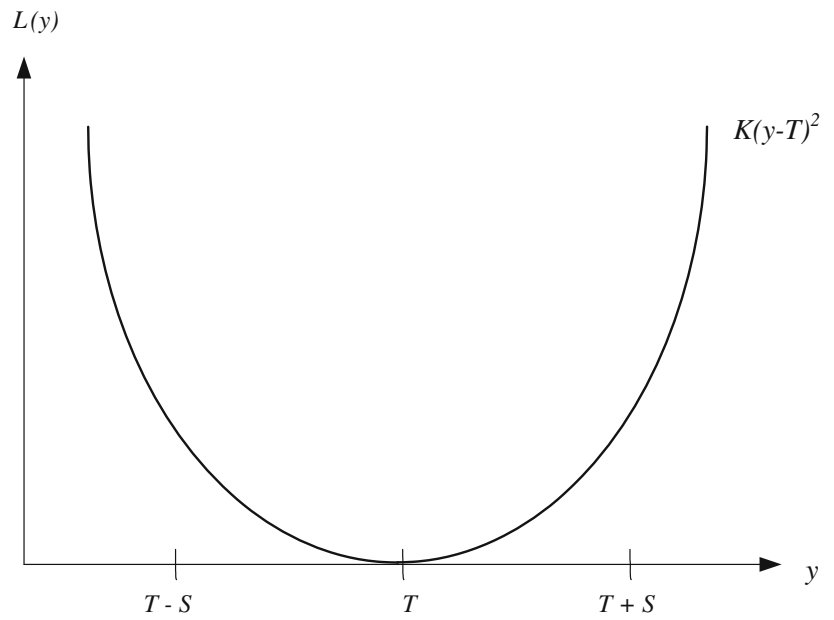

Fig. 2 Quality loss function

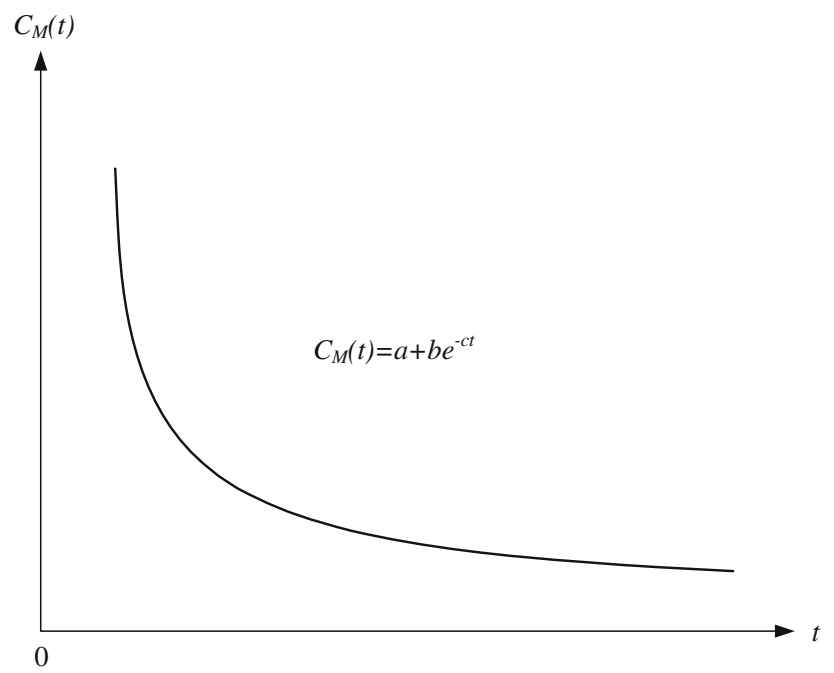

Fig. 3 Tolerance cost function

$C_{p m c}=\frac{U S L-L S L}{6\left(\sqrt{K\left[\sigma^{2}+(U-T)^{2}\right]}+C_{M}\left(t_{i}\right)\right)}$

where $\sigma$ is $t / P$ and $C_{M}(t)$ is given value or $a+b e^{-c t}$ (Jeang 1994, 1995), $K$ is $C_{A} / S^{2}$.

Because the process capability is a production process's capability of producing a product according to the desired expectation of customers, the advantage in adopting $C_{p m c}$ as the observed response for process design is that the designed parameter and tolerance values must represent the capability of producing a quality and cost-effective product. Then, by following the designed values, the production processes have the capability of producing products meeting customers' expectations. Thus, instead of other responses used in previous works, the $C_{p m c}$ value is considered as observed responses in the present research.

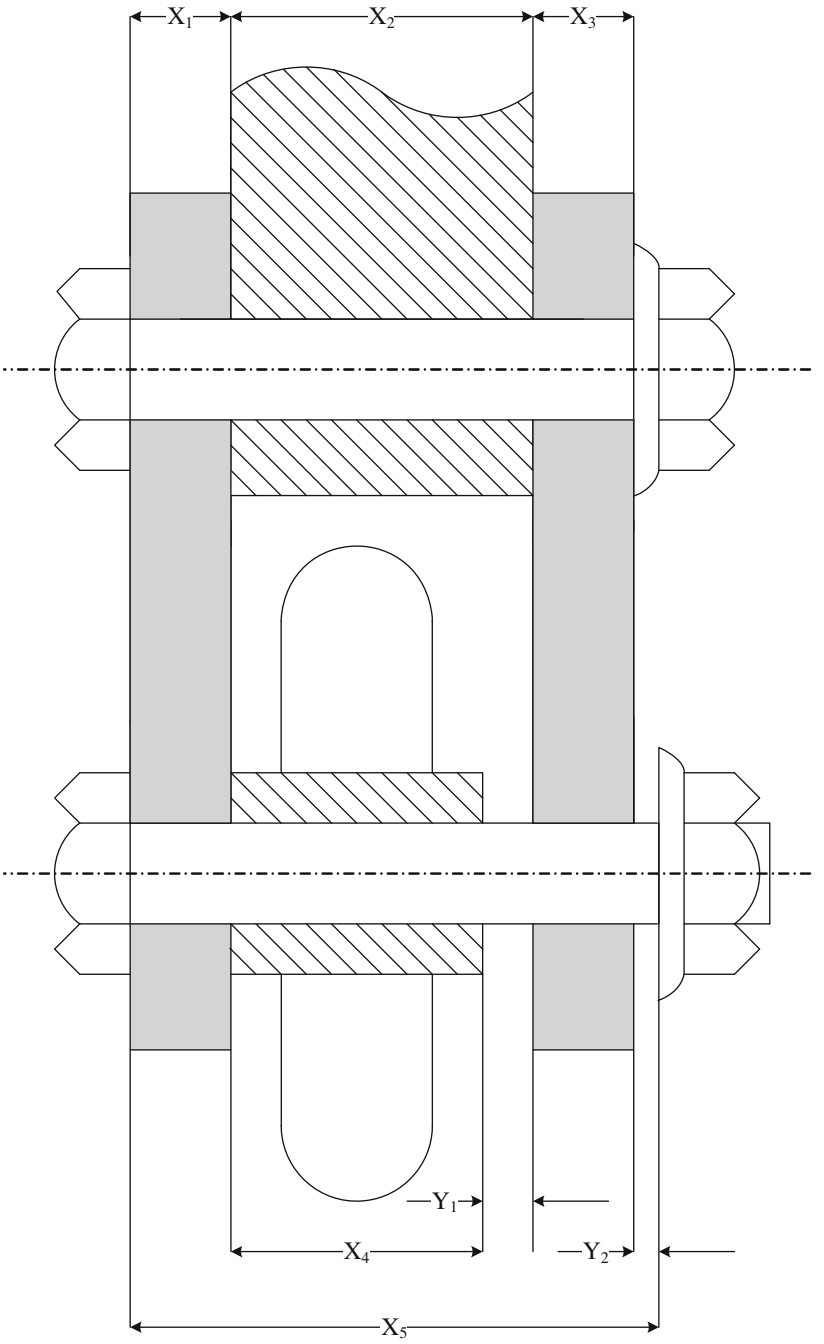

Fig. 4 The wheel mounting assembly drawing

\section{The application for product design and process planning}

Example 1 Assembly is the process by which the various parts and subassemblies are brought together to form a completed assembly or product which is designed to fulfill a certain mechanical function. Since assembly in the manufacturing process consists of putting together all the component parts and subassemblies of a given product, a proper allocation and analysis of tolerances among the assembly components is important to ensure that the functionality and quality of the design requirement are met. However, from the preceding discussion, in addition to tolerance design, the element of component dimensions (parameter values) should also be considered in an assembly design.

Figure 4 is a wheel mounting assembly, which consists of components $X_{1}, X_{2}, X_{3}, X_{4}$ and $X_{5}$. They are linked with 
Table 1 Three levels, $U_{j}$ and $t_{j}$, for each component and tolerance $\operatorname{cost} C_{M}\left(t_{j}\right)$

\begin{tabular}{llll}
\hline Component $\mathrm{j}$ & Lower level & Middle level & Upper level \\
\hline$U_{1}$ & $4.9654 \mathrm{~mm}$ & $5.0000 \mathrm{~mm}$ & $5.0346 \mathrm{~mm}$ \\
$U_{2}$ & $8.4740 \mathrm{~mm}$ & $8.5000 \mathrm{~mm}$ & $8.5260 \mathrm{~mm}$ \\
$U_{3}$ & $3.9654 \mathrm{~mm}$ & $4.0000 \mathrm{~mm}$ & $4.0346 \mathrm{~mm}$ \\
$U_{4}$ & $8.3311 \mathrm{~mm}$ & $8.3600 \mathrm{~mm}$ & $8.3889 \mathrm{~mm}$ \\
$U_{5}$ & $17.6740 \mathrm{~mm}$ & $17.7000 \mathrm{~mm}$ & $17.7260 \mathrm{~mm}$ \\
$t_{1}$ & $\$ 10.7702(0.03 \mathrm{~mm})$ & $\$ 10.7653(0.06 \mathrm{~mm})$ & $\$ 10.7543(0.09 \mathrm{~mm})$ \\
$t_{2}$ & $\$ 12.7705(0.02 \mathrm{~mm})$ & $\$ 12.7618(0.04 \mathrm{~mm})$ & $\$ 12.7437(0.06 \mathrm{~mm})$ \\
$t_{3}$ & $\$ 10.7702(0.03 \mathrm{~mm})$ & $\$ 10.7653(0.06 \mathrm{~mm})$ & $\$ 10.7543(0.09 \mathrm{~mm})$ \\
$t_{4}$ & $\$ 5.7009(0.04 \mathrm{~mm})$ & $\$ 5.6971(0.06 \mathrm{~mm})$ & $\$ 5.6879(0.08 \mathrm{~mm})$ \\
$t_{5}$ & $\$ 7.1243(0.03 \mathrm{~mm})$ & $\$ 7.1227(0.05 \mathrm{~mm})$ & $\$ 7.1185(0.07 \mathrm{~mm})$ \\
\hline
\end{tabular}

two interrelated tolerance and dimension chains. The assembly functions for representing these two dimension chains are:

$$
\begin{aligned}
& Y_{1}=X_{2}-X_{4} \\
& Y_{2}=-X_{1}-X_{2}-X_{3}+X_{5}
\end{aligned}
$$

The associated component dimensions and tolerances, $U_{1}, U_{2}, U_{3}, U_{4}$ and $U_{5}, t_{1}, t_{2}, t_{3}, t_{4}$ and $t_{5}$, must be determined simultaneously (Jeang and Chang 2002). The target values $T_{1}$ and $T_{2}$ are 0.14 and $0.20 \mathrm{~mm}$, respectively. The matching quality loss coefficients $K_{1}$ and $K_{2}$ are 250 and 350 . The design tolerances (specifications) $S_{1}$ and $S_{2}$ are 0.12 and $0.16 \mathrm{~mm}$, respectively. Obviously, USL-LSL for $Y_{1}$ and $Y_{2}$ is $2 S_{1}$ and $2 S_{2}$ correspondingly. For the purpose of demonstration in an off-line application, the PCI expression $C_{p m c}$ will be used as an index in measuring quality characteristics $Y_{1}$ and $Y_{2}$. The high, middle, low tolerance levels and the associated tolerance cost are illustrated in Table 3 . The feasible ranges for parameter $U_{i}$ and the process capability limits for $t_{i}$ are the extreme values connected with high and low levels in Table 1. Certainly, rooted in the discussion in Sect. 5, the formulation must contain decision variables, which are component parameters, $U_{1}, U_{2}, U_{3}, U_{4}$ and $U_{5}$, and tolerances, $t_{1}, t_{2}, t_{3}, t_{4}$ and $t_{5}$. They must be determined simultaneously to ensure $C_{p m c}$ is maximized (Jeang and Chang 2002). The Monte Carlo Simulation is performed with the various level combinations of $U_{i}$ and $t_{i}$, as suggested in "Appendix A". The normality assumption, $X_{i-} N\left(U_{i}, \sigma\left(t_{i}\right)\right)$, is used to generate random values $X_{1}, X_{2}, X_{3}, X_{4}$ and $X_{5}$ in $\mathrm{e}^{\text {th }}$ experimental run where $\sigma\left(t_{i}\right)$ is defined in Eq. (10).

$\sigma\left(t_{i}\right)=\left(\frac{t_{i}}{3}\right)$

These random values are plugged into the above Eqs. (8) and (9) to have one set of $Y_{1}$, and $Y_{2}$ correspondingly. Each level combination of $U_{i}$ and $t_{i}$ will be repeated 30 times in the $e^{\text {th }}$ experimental run to ensure the accuracy of the normality assumption. Then, the outputs, $U_{Y r}$ and $\sigma_{Y r}$, can be obtained in the $\mathrm{e}^{\text {th }}$ experimental run, where $\mathrm{r}$ is 1 and 2. The response values, $C_{p m c 1}$ and $C_{p m c 2}$ are found from Eq. (7). Then, having $C_{p m c}$ as the response value, the RSM optimization technique is used for problem analysis. $C_{p m c}$ is defined in the following equation:

$C_{p m c}=\frac{C_{p m c 1}+C_{p m c 2}}{2}$

The optimal solutions are $t_{1}^{*}=0.0439, t_{2}^{*}=0.0600$, $t_{3}^{*}=0.0439, t_{4}^{*}=0.0759, t_{5}^{*}=0.0446, U_{1}^{*}=4.9654, U_{2}^{*}=$ $8.5260, U_{3}^{*}=3.9825, U_{4}^{*}=8.3860, U_{5}^{*}=17.6740$ and $C_{p m c}^{*}=0.0069$. A second-order model $C_{p m c}$ predicting equation is: $0.4739-0.0083 U_{1}-0.0095 U_{2}-$ $0.0124 U_{3}-0.0201 U_{4}-0.0336 U_{5}-0.0101 U_{1}^{2}-0.0215 U_{1}$ $U_{2}-0.0371 U_{2}^{2}-0.0217 U_{1} U_{3}-0.0219 U_{2} U_{3}-0.0101 U_{3}^{2}+$ $0.0551 U_{2} U_{4}-0.0268 U_{4}^{2}+0.02144 U_{1} U_{5}+0.0212 U_{2} U_{5}+$ $0.0219 U_{3} U_{5}-0.0097 U_{5}^{2}+0.0002 U_{1} t_{1}+0.0002 U_{3} t_{1}-$ $0.0001 U_{5} t_{1}-0.0005 t_{1}^{2}-0.0049 t_{2}^{2}-0.0048 t_{3}^{2}-0.0082 t_{3}$ $t_{4}-0.0117 t_{4}^{2}+0.0082 t_{3} t_{5}+0.0186 t_{4} t_{5}-0.0092 t_{5}^{2}$. Table 2 shows that the $R^{2}$ value is 0.9979 . The fact that the $R^{2}$ value is greater than 0.95 indicates that the second order model provides an excellent fit. For statistical analysis, as completed by the computer programs, SAS (SAS Institute 2001), the contour and surface of the response of $C_{p m c}$ is plotted in Figs. 5 and 6 to illustrate its 3D shape. Each contour represents a specific response value for combinations of the levels of factors. Various level combinations will be examined so that design feasibility and restrictions are satisfied. In addition, the F-ratio and F-ordering for all inputs $U_{i}$ and $t_{i}$ are listed in Table 3. F-ratio and F-ordering indicate that $U_{2}, U_{3}$ and $U_{1}$ should be closely controlled. If design improvement is needed, component 2 is to be given first priority.

For the purpose of comparison with other optimization methods, Example 1 is formulated with the mathematical programming as given in "Appendix B". The optimal solutions found from "Appendix B" are very close to the values obtained in the proposed approach. The solution closeness 
Table 2 Statistical analysis for $C_{p m c}$ of Example 1

\begin{tabular}{|c|c|c|c|c|c|}
\hline \multicolumn{6}{|c|}{ Response surface for variable $C_{p m c}$} \\
\hline \multicolumn{5}{|c|}{ Response mean } & 0.006908 \\
\hline \multicolumn{5}{|l|}{ Root MSE } & 0.000000181 \\
\hline \multicolumn{5}{|l|}{ R-square } & 0.9979 \\
\hline \multicolumn{5}{|c|}{ Coefficient of variation } & 0.4648 \\
\hline Regression & DF & S S & R-Square & F value & $\operatorname{Pr}>F$ \\
\hline Linear & 10 & $4.8437 \mathrm{E}-9$ & 0.0424 & 14865.9 & $<0.0001$ \\
\hline Quadratic & 10 & $3.1978 \mathrm{E}-8$ & 0.2797 & 98144.2 & $<0.0001$ \\
\hline Crossproduct & 45 & $7.74886 \mathrm{E}-8$ & 0.6779 & 52848.7 & $<0.0001$ \\
\hline Total Model & 65 & 0.000000114 & 1.0000 & 53973.7 & $<0.0001$ \\
\hline Factor & $\begin{array}{l}\text { Degrees of } \\
\text { freedom }\end{array}$ & Sum of squares & Mean square & Prob $>$ F & \\
\hline$U_{1}$ & 11 & $2.6443291 \mathrm{E}-8$ & $2.4039356 \mathrm{E}-9$ & $<0.0001$ & \\
\hline$U_{2}$ & 11 & $4.3891891 \mathrm{E}-8$ & $3.9901719 \mathrm{E}-9$ & $<0.0001$ & \\
\hline$U_{3}$ & 11 & $3.2048017 \mathrm{E}-8$ & $2.913456 \mathrm{E}-9$ & $<0.0001$ & \\
\hline$U_{4}$ & 11 & $2.8242178 \mathrm{E}-8$ & $2.5674708 \mathrm{E}-9$ & $<0.0001$ & \\
\hline$U_{5}$ & 11 & $2.3253698 \mathrm{E}-8$ & $2.1139726 \mathrm{E}-9$ & $<0.0001$ & \\
\hline$t_{1}$ & 11 & $1.170191 \mathrm{E}-10$ & $1.06381 \mathrm{E}-11$ & $<0.0001$ & \\
\hline$t_{2}$ & 11 & $3.1594869 \mathrm{E}-9$ & $2.872261 \mathrm{E}-10$ & $<0.0001$ & \\
\hline$t_{3}$ & 11 & $1.233381 \mathrm{E}-10$ & $1.121255 \mathrm{E}-11$ & $<0.0001$ & \\
\hline$t_{4}$ & 11 & $7.152263 \mathrm{E}-10$ & $6.502057 \mathrm{E}-11$ & $<0.0001$ & \\
\hline$t_{5}$ & 11 & $2.986217 \mathrm{E}-11$ & $2.714743 \mathrm{E}-12$ & $<0.0001$ & \\
\hline
\end{tabular}

Fig. 5 Response surface

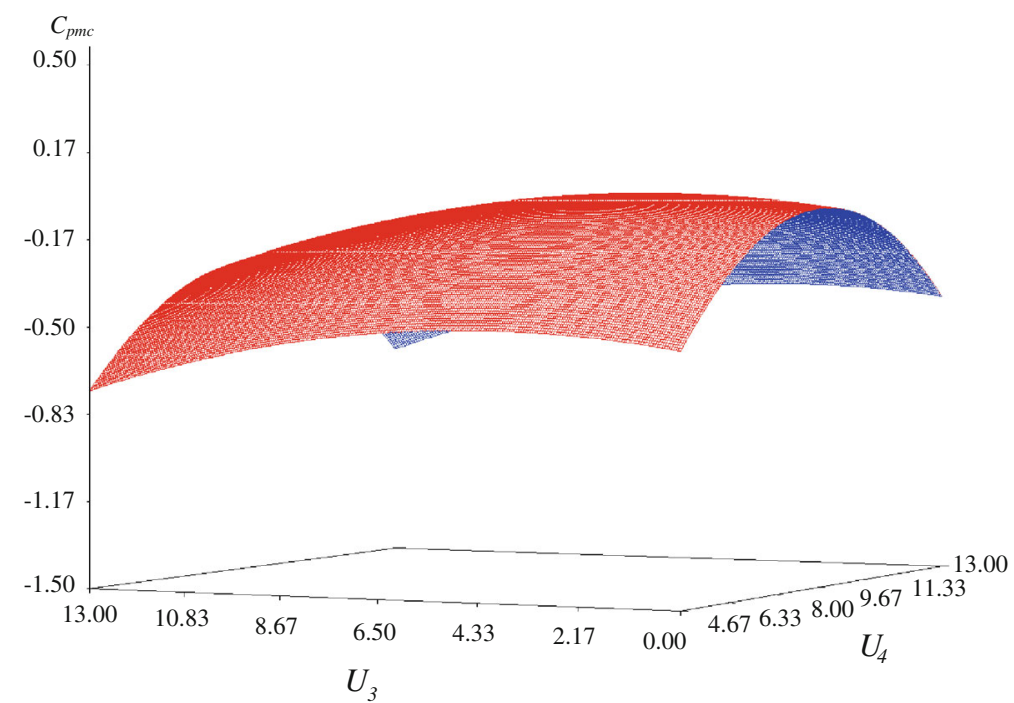

may be because of this particular example. However, there are still some advantages with the proposed approach. They are: (1) Other than determining the optimal solutions, the proposed approach also provided the important ranking listed in Table 3 as a reference for design improvement. (2) Because "Appendix B" shows a deterministic approach, design functions, Eqs. (8-9), tolerance cost functions, $a+b \cdot e^{-c \cdot t}$, need to be well defined in advance. However, sometimes design functions are unknown, and tolerance cost $C_{M}(t)$ from tolerance function $a+b \cdot e^{-c \cdot t}$ and the quality loss coefficient $K$ from $C_{A} / S^{2}$ are stochastic in nature. These facets render the deterministic approach in "Appendix B" infeasible. Conversely, the proposed approach is well adapted for design in an uncertain environment. When the constraints of Eqs. (3342) on decision variables appear in nonlinear forms, the proposed approach becomes infeasible. 


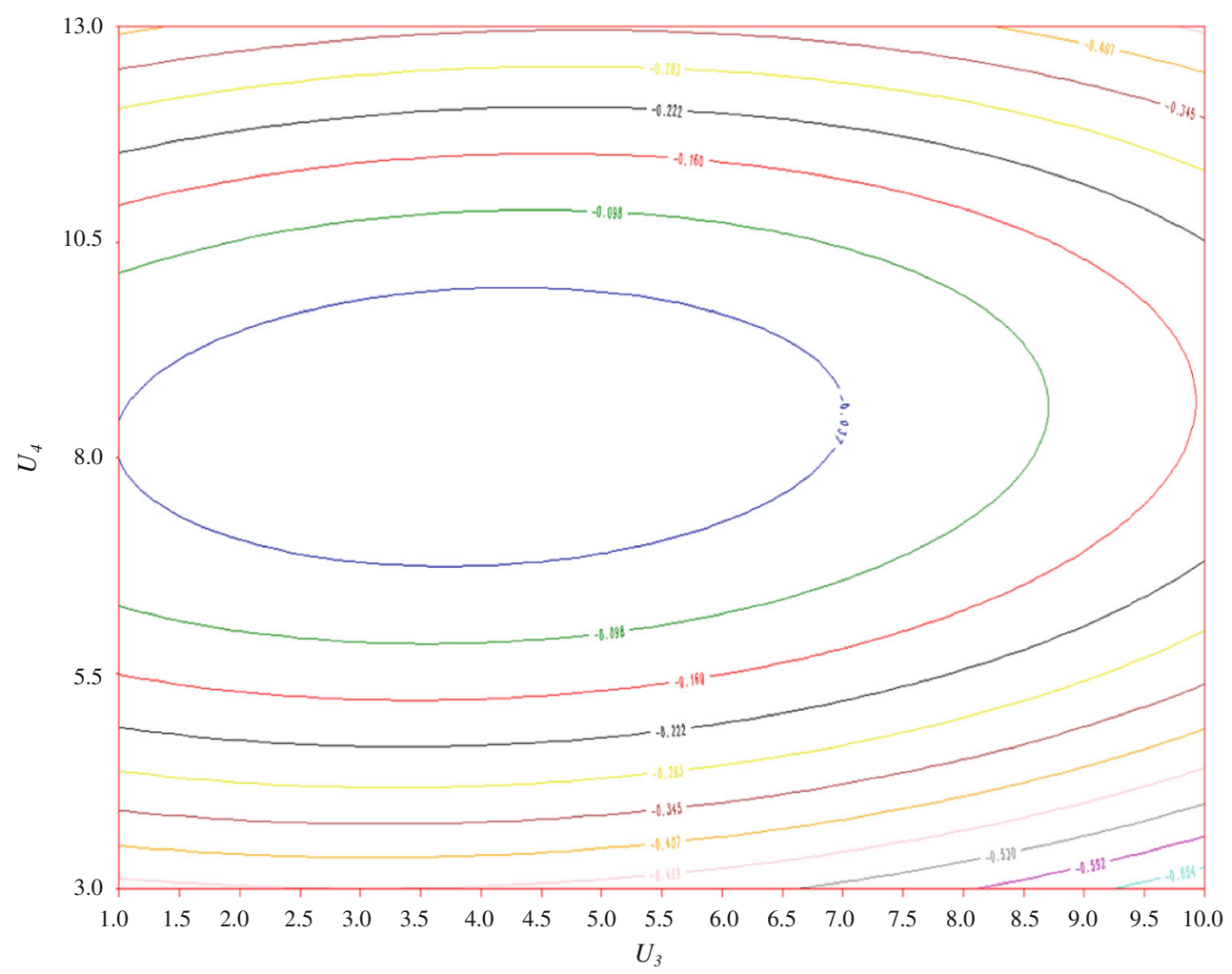

Fig. 6 Contour plot of $C_{p m c}$ for process mean $U_{3}$ and $U_{4}$

Table 3 F-ratio and F-ranking

\begin{tabular}{lrl}
\hline Factors & \multicolumn{1}{c}{ F-ratio } & F-ranking \\
\hline$U_{1}$ & 73778.80 & 3 \\
$U_{2}$ & 122462.00 & 1 \\
$U_{3}$ & 89416.40 & 2 \\
$U_{4}$ & 78797.80 & 4 \\
$U_{5}$ & 64879.60 & 5 \\
$t_{1}$ & 326.49 & 9 \\
$t_{2}$ & 8815.21 & 6 \\
$t_{3}$ & 344.12 & 8 \\
$t_{4}$ & 1995.54 & 7 \\
$t_{5}$ & 83.32 & 10 \\
\hline
\end{tabular}

Example 2 A practical example of manufacturing process planning is introduced to illustrate how the presented approach is applied to machining operations. Figure 7 is a drawing of the work piece. The various combinations of component dimension values $X_{1}, X_{2}, X_{3}, X_{4}$ and $X_{5}$ from each cutting operation result in five $B / P$ dimension values, $Y_{1}, Y_{2}, Y_{3}, Y_{4}$ and $Y_{5}$. Table 4 shows the procedures for the manufacturing process, which include the working machine, the reference surface, the processed surface, and the process capability range allowed in the manufacturing process. Table 5 is the related information concerning the
$\mathrm{B} / \mathrm{P}$ dimensions. It covers the $\mathrm{DC}, \mathrm{DC}$ vector, design tolerance $S_{r}$, design target $T_{r}$ and quality loss coefficient $K_{r}$, where $r$ is $1,2,3 \ldots 5$. As mentioned in the preceding discussion, the associated process means and process tolerances are $U_{1}, U_{2}, U_{3}, U_{4}$ and $U_{5}, t_{1}, t_{2}, t_{3}, t_{4}$ and $t_{5}$. These values must be determined simultaneously so that all $\mathrm{B} / \mathrm{P}$ dimension values fall within their own specification limits. By referring to dimension chain DC vector, $A_{r e}$, in Table 5, the design functions are formed as follows:

$Y_{1}=X_{5}+X_{4}$

$Y_{2}=X_{3}-X_{1}$

$Y_{3}=X_{3}-X_{2}$

$Y_{4}=X_{4}-X_{3}$

$Y_{5}=X_{5}$

If we let the optimal solutions, $U^{*}$ and $t^{*}$, found from $C_{p m c}$ as an objective function, be substituted into the $C_{p m}$ expression to have $C_{p m}^{\prime}$, the values $C_{p m}^{\prime}, 1.2756$, still fall above the acceptable limit for general application. Accordingly, the optimal solutions $U^{*}$ and $t^{*}$ not only maximize the $C_{p m c}$ expression, but also ensure that the $C_{p m}$ value is at a satisfactory level.

The low, middle and high levels for input factors $U_{i}$, and $t_{i}$ and associated tolerance costs are shown in Table 6. The Monte Carlo Simulation is performed with the various level 
Fig. 7 The Part for the presented machining process

Table 4 The operations involved in the manufacturing process

Table 5 Related information on the work piece diagram

Table 6 Three levels, $U_{i}$ and $t_{i}$, for each operation and tolerance $\operatorname{cost} C_{M}\left(t_{i}\right)$
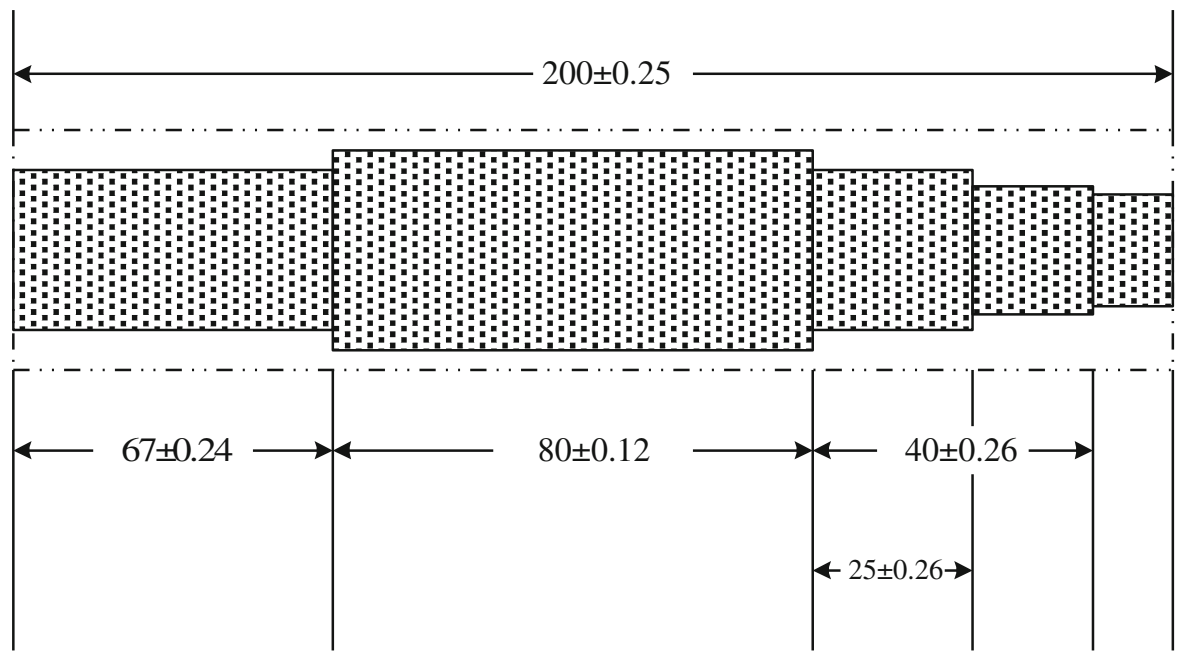

A

B

C

D

E $F$

\begin{tabular}{llllll}
\hline $\begin{array}{l}\text { Operation } \\
\text { number } \\
i\end{array}$ & $\begin{array}{l}\text { Working } \\
\text { machine }\end{array}$ & $\begin{array}{l}\text { Reference } \\
\text { surface }\end{array}$ & $\begin{array}{l}\text { Processed } \\
\text { surface }\end{array}$ & $\begin{array}{l}\text { Lower process } \\
\text { capability } \\
t_{L i}(\mathrm{~mm})\end{array}$ & $\begin{array}{l}\text { Upper process } \\
\text { capability } \\
t_{U i}(\mathrm{~mm})\end{array}$ \\
\hline 1 & Turret lathe & F & E & 0.04 & 0.14 \\
2 & Turret lathe & F & D & 0.04 & 0.14 \\
3 & Turret lathe & F & C & 0.05 & 0.13 \\
4 & Turret lathe & F & B & 0.05 & 0.13 \\
5 & Turret lathe & B & A & 0.05 & 0.13 \\
\hline
\end{tabular}

\begin{tabular}{llllllr}
\hline$r$ & $\begin{array}{l}\text { Blueprint } \\
\text { dimensions }\end{array}$ & $\begin{array}{l}\text { Dimension } \\
\text { chain } \\
r\end{array}$ & $\begin{array}{l}\text { Dimensions } \\
\text { chain vector } \\
A_{r e}\end{array}$ & $\begin{array}{l}\text { Design } \\
\text { tolerance } \\
S_{r}\end{array}$ & $\begin{array}{l}\text { Target } \\
\text { value } \\
T_{r}\end{array}$ & $\begin{array}{l}\text { Quality } \\
\text { loss coef. } \\
K_{r}\end{array}$ \\
\hline 1 & A-F & $5-4$ & {$[1,1]$} & 0.25 & 200 & 6,000 \\
2 & C-E & $3-1$ & {$[1,-1]$} & 0.26 & 41 & 10,500 \\
3 & C-D & $3-2$ & {$[1,-1]$} & 0.26 & 25 & 9,000 \\
4 & B-C & $4-3$ & {$[1,-1]$} & 0.12 & 79 & 1,500 \\
5 & A-B & 5 & {$[1]$} & 0.24 & 42 & 10,500 \\
\hline
\end{tabular}

\begin{tabular}{llll}
\hline Operation $i$ & Lower level & Middle level & Upper level \\
\hline$U_{1}$ & $38 \mathrm{~mm}$ & $39 \mathrm{~mm}$ & $40 \mathrm{~mm}$ \\
$U_{2}$ & $55 \mathrm{~mm}$ & $56 \mathrm{~mm}$ & $57 \mathrm{~mm}$ \\
$U_{3}$ & $79 \mathrm{~mm}$ & $81 \mathrm{~mm}$ & $82 \mathrm{~mm}$ \\
$U_{4}$ & $157 \mathrm{~mm}$ & $160 \mathrm{~mm}$ & $163 \mathrm{~mm}$ \\
$U_{5}$ & $42 \mathrm{~mm}$ & $43 \mathrm{~mm}$ & $44 \mathrm{~mm}$ \\
$t_{1}$ & $\$ 93.0028(0.04) \mathrm{mm}$ & $\$ 71.1156(0.09) \mathrm{mm}$ & $\$ 63.0939(0.14) \mathrm{mm}$ \\
$t_{2}$ & $\$ 93.7241(0.04) \mathrm{mm}$ & $\$ 71.3709(0.09) \mathrm{mm}$ & $\$ 63.0717(0.14) \mathrm{mm}$ \\
$t_{3}$ & $\$ 78.5737(0.05) \mathrm{mm}$ & $\$ 56.9872(0.09) \mathrm{mm}$ & $\$ 50.5266(0.13) \mathrm{mm}$ \\
$t_{4}$ & $\$ 79.4912(0.05) \mathrm{mm}$ & $\$ 57.2412(0.09) \mathrm{mm}$ & $\$ 50.5153(0.13) \mathrm{mm}$ \\
$t_{5}$ & $\$ 79.4991(0.05) \mathrm{mm}$ & $\$ 57.2688(0.09) \mathrm{mm}$ & $\$ 50.5201(0.13) \mathrm{mm}$ \\
\hline
\end{tabular}


Table 7 Statistical analysis for $C_{p m c}$

\begin{tabular}{|c|c|c|c|c|c|}
\hline \multicolumn{6}{|c|}{ Response surface for variable $C_{p m c}$} \\
\hline \multicolumn{5}{|l|}{ Response mean } & 0.007992 \\
\hline \multicolumn{5}{|l|}{ Root MSE } & 0.001249 \\
\hline \multicolumn{5}{|l|}{$R^{2}$} & 0.9624 \\
\hline \multicolumn{5}{|c|}{ Coefficient of variation } & 15.6241 \\
\hline Regression & DF & S S & R-square & F value & $\operatorname{Pr}>F$ \\
\hline Linear & 10 & 0.000584 & 0.1356 & 37.47 & $<0.0001$ \\
\hline Quadratic & 10 & 0.003526 & 0.8183 & 226.14 & $<0.0001$ \\
\hline Crossproduct & 45 & 0.0000363 & 0.0084 & 0.52 & 0.9927 \\
\hline Total Model & 65 & 0.004147 & 0.9624 & 40.91 & $<0.0001$ \\
\hline Factors & $\begin{array}{l}\text { Degrees of } \\
\text { freedom }\end{array}$ & Sum of squares & Mean square & Prob $>$ F & \\
\hline$U_{1}$ & 11 & 0.000010044 & 0.000000913 & 0.8368 & \\
\hline$U_{2}$ & 11 & 0.000015449 & 0.000001404 & 0.5425 & \\
\hline$U_{3}$ & 11 & 0.000127 & 0.000011517 & $<0.0001$ & \\
\hline$U_{4}$ & 11 & 0.000276 & 0.000025111 & $<0.0001$ & \\
\hline$U_{5}$ & 11 & 0.000010136 & 0.000000921 & 0.8325 & \\
\hline$t_{1}$ & 11 & 0.000001496 & 0.000000136 & 1.0000 & \\
\hline$t_{2}$ & 11 & 0.000002247 & 0.000000204 & 0.9996 & \\
\hline$t_{3}$ & 11 & 0.000013530 & 0.000001230 & 0.6506 & \\
\hline$t_{4}$ & 11 & 0.000042951 & 0.000003905 & 0.0078 & \\
\hline$t_{5}$ & 11 & 0.000094262 & 0.000008569 & $<0.0001$ & \\
\hline
\end{tabular}

combinations of $U_{i}$ and $t_{i}$, as suggested in "Appendix A. The normality assumption, $X_{i \_} N\left(U_{i}, \sigma\left(t_{i}\right)\right)$, is used to generate experimental values $X_{1}, X_{2}, X_{3}, X_{4}$ and $X_{5}$ randomly in $\mathrm{e}^{\text {th }}$ experimental run. These experimental values are plugged into the above Eqs. (12)-(16) to have one set of $Y_{1}, Y_{2}, Y_{3}, Y_{4}$ and $Y_{5}$, correspondingly. Each level combination of $U_{i}$ and $t_{i}$ will be repeated 30 times in $\mathrm{e}^{\text {th }}$ experimental run to ensure the accuracy of the normality assumption. Then, $U_{Y r}$ and $\sigma_{Y s}$ are obtained from 30 sets of $Y_{1}, Y_{2}, Y_{3}, Y_{4}$ and $Y_{5}$, where $r$ is 1 , 2, 3, 4 and 5. The values, $C_{p m c 1}, C_{p m c 2}, C_{p m c 3}, C_{p m c 4}$ and $C_{p m c 5}$, can be found from Eq. (7) with the $\mathrm{e}^{\text {th }}$ experimental outputs, $U_{Y r}$ and $\sigma_{Y s}$. Then, the response value is the sum of $C_{p m c 1}, C_{p m c 2}, C_{p m c 3}, C_{p m c 4}$ and $C_{p m c 5}$, which is considered as the response value for RSM analysis. A second-order model $C_{p m c}$ predicting equation is: $-24.8924+0.4539 U_{3}+$ $0.0923 U_{4}+0.0005 U_{2} U_{3}-0.0031 U_{3}^{2}-0.0003 U_{4}^{2}+0.0002$ $U_{4} U_{5}-3.5787 t_{3}^{2}-4.0503 t_{4}^{2}$. Table 7 indicates that the coefficient of determination $R^{2}$ is 0.9624 , and that a good fit exists. The optimal solutions are $t_{1}^{*}=0.0908, t_{2}^{*}=0.0898, t_{3}^{*}=$ $0.0904, t_{4}^{*}=0.0892, t_{5}^{*}=0.0891, U_{1}^{*}=38.9456, U_{2}^{*}=$ 56.0464, $U_{3}^{*}=80.5716, U_{4}^{*}=158.8937, U_{5}^{*}=42.8089$, $C_{p m c}^{*}=0.01712$ and $C_{p m}^{\prime}=1.3972$. For statistical analysis as completed by the computer programs, SAS (SAS Institute 2001), the contour and surface of the response of $C_{p m c}$ is plotted in Figs. 8 and 9 to illustrate its 3D shape.
In addition, the F-ratio and F-ordering for all inputs $U_{i}$ and $t_{i}$ are listed in Table 8. F-ratio and F-ordering indicate that $U_{3}, U_{4}, t_{4}$ and $t_{5}$ should be closely controlled. If process improvement is needed, operation 4 is to be given first priority.

\section{Summary}

The present research uses the PCI measurement, $C_{p m c}$, via RSM for robustness in process capability analysis to ensure that, at the initial blueprint stage, a lower production cost and a high quality product can be achieved. A time frame is developed for the off-line applications during product and process design. Prior to production, design engineers can establish process mean and process tolerance based on the optimized mean and tolerance values, and make use of the listed ranking as a reference for possible design improvement. As expected, the produced quality values after the production process must be distributed with statistical values as the established process mean and process tolerance before the production process. As a result, an effective PCI for a product's life cycle becomes actualized. Two examples: product design and process planning, are introduced for demonstrating the present approach. The results, in terms 
Fig. 8 Response surface
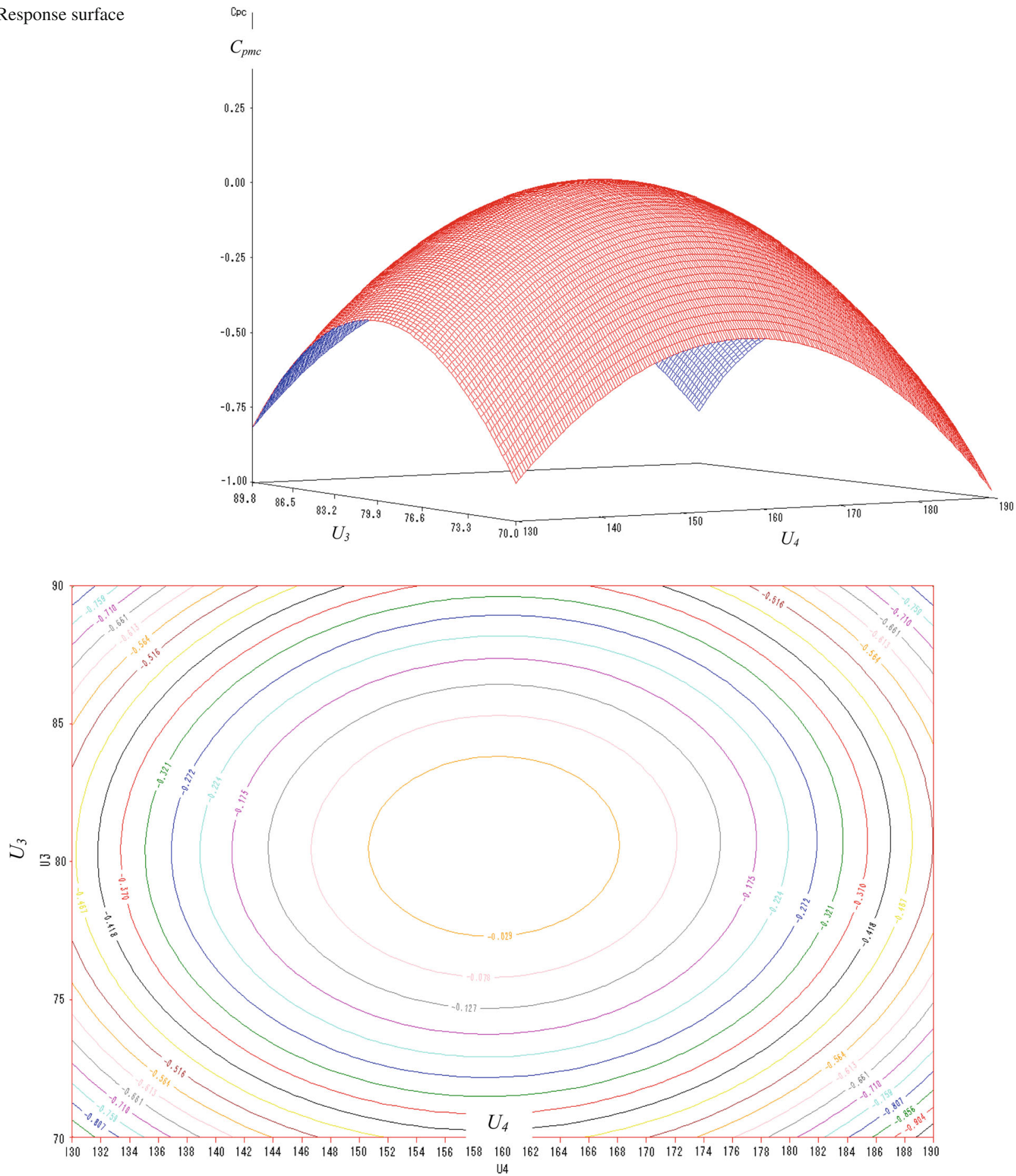

Fig. 9 Contour plot of $C_{p m c}$ for process mean $U_{3}$ and $U_{4}$

of statistical sense, provide not only the optimal solutions but also the important ranking. Because previous works considered the tolerance costs and quality losses as deterministic values in product and process design, there is a need to relax the assumptions of deterministic values in future research. The present approach considers product specifications $U S L$ and $L S L$ as given conditions; there is a need to relax this given assumption in future studies, by considering USL and $L S L$ as additional decision variables. Most of the time, during design and planning stages, design functions such as Eqs. (8-9) and (12-16) are unknown. Utilizing advanced computer software, such as Computer-Aided Engineering (CAE), can help engineers at the product design and process planning stage, to surmount design problems that 
Table 8 F-ratio and F-ranking

\begin{tabular}{lrl}
\hline Factors & F-ratio & F-ranking \\
\hline$U_{1}$ & 0.59 & 7 \\
$U_{2}$ & 0.90 & 5 \\
$U_{3}$ & 7.39 & 2 \\
$U_{4}$ & 16.10 & 1 \\
$U_{5}$ & 0.59 & 8 \\
$t_{1}$ & 0.09 & 10 \\
$t_{2}$ & 0.13 & 9 \\
$t_{3}$ & 0.79 & 6 \\
$t_{4}$ & 2.50 & 4 \\
$t_{5}$ & 5.50 & 3 \\
\hline
\end{tabular}

have unknown design functions. As a result, an economical and quality process capability analysis for product and process design becomes possible at an earlier time in the design stage. The following itemizes and explains the steps involved:

Step 1: Provide the design functions (see Eqs. 8-9 and 12-16) and the design-related information (see Tables 4, $5)$. Offer $L S L, U S L, C_{A}$, tolerance cost functions or tolerance costs.

Step 2: Choose an appropriate design experimental matrix (see "Appendix A") for the various levels of inputs, $U$ and $t$ (see Tables 1,6).

Step 3: Use the combined levels of inputs, $U$ and $t$, as the arrangement of an experimental design matrix to find: a) $K\left[\sigma^{2}+(U-T)^{2}\right], \sigma^{2}=(t / P)^{2}$, normally $P=3, K$ is $\left.C_{A} / S^{2}, \mathbf{b}\right) C_{M}(t)$ is $a+b e^{-c t}$ or tolerance cost with given tolerance level (see Table 1 or Table 6 ). Then have the results from items a and b fed into Eq. (7) to find $C_{p m c}$. Step 4: Perform RSM with SAS software to obtain the best values of $U$ and $t$ for the maximization of $C_{p m c}$ and to find $\mathrm{Cpmc}$ prediction functions by regression analysis. See second-order model $C_{p m c}$ predicting equation in Examples 1 and 2. Then, employ ANOVA to rank the important parameters (see Tables 3, 8).

Step 5: Employ ANOVA to rank the important parameters (see Tables 3, 8).

Step 6: If improvement is needed, then the above steps can be repeated based on the suggestions made in Step 5 .

Acknowledgments This research was carried out in the Design, Quality, and Productivity Laboratory (DQPL) at the Department of Industrial Engineering and Systems Management at Feng Chia University, Taichung, Taiwan.

Open Access This article is distributed under the terms of the Creative Commons Attribution License which permits any use, distribution, and reproduction in any medium, provided the original author(s) and the source are credited.
Appendix A: Table of Box-Behnken Design

$($ Factors $=10$, blocks $=2$, runs $=170)$

$$
\left(\begin{array}{llllllllll}
0 & \pm 1 & 0 & 0 & 0 & \pm 1 & \pm 1 & 0 & 0 & \pm 1 \\
\pm 1 & \pm 1 & 0 & 0 & \pm 1 & 0 & 0 & 0 & 0 & \pm 1 \\
0 & \pm 1 & \pm 1 & 0 & 0 & 0 & \pm 1 & \pm 1 & 0 & 0 \\
0 & \pm 1 & 0 & \pm 1 & 0 & \pm 1 & 0 & 0 & \pm 1 & 0 \\
\pm 1 & 0 & 0 & 0 & 0 & 0 & 0 & \pm 1 & \pm 1 & \pm 1 \\
0 & 0 & \pm 1 & \pm 1 & \pm 1 & 0 & 0 & 0 & 0 & \pm 1 \\
\pm 1 & 0 & 0 & \pm 1 & 0 & 0 & \pm 1 & \pm 1 & 0 & 0 \\
0 & 0 & \pm 1 & 0 & \pm 1 & 0 & \pm 1 & 0 & \pm 1 & 0 \\
\pm 1 & 0 & \pm 1 & 0 & 0 & \pm 1 & 0 & 0 & \pm 1 & 0 \\
0 & 0 & 0 & \pm 1 & \pm 1 & \pm 1 & 0 & \pm 1 & 0 & 0 \\
0 & 0 & 0 & 0 & 0 & 0 & 0 & 0 & 0 & 0
\end{array}\right)
$$

\section{Appendix B: Presented problem formulated with mathematical programming}

$\operatorname{Max} \quad C_{p m c}=\frac{C_{p m c_{1}}+C_{p m c_{2}}}{2}$

s.t.

$$
\begin{aligned}
& t_{Y 1}=t_{2}+t_{4} \\
& t_{Y 2}=t_{1}+t_{2}+t_{3}+t_{5} \\
& \sigma_{Y 1}=\sqrt{\left(\frac{t_{2}}{P}\right)^{2}+\left(\frac{t_{4}}{P}\right)^{2}} \\
& \sigma_{Y 2}=\sqrt{\left(\frac{t_{1}}{P}\right)^{2}+\left(\frac{t_{2}}{P}\right)^{2}+\left(\frac{t_{3}}{P}\right)^{2}+\left(\frac{t_{5}}{P}\right)^{2}} \\
& U_{Y 1}=U_{2}-U_{4} \\
& U_{Y 2}=-U_{1}-U_{2}-U_{3}+U_{5} \\
& C_{M}\left(t_{Y 1}\right)=a_{2}+b_{2} \cdot e^{-c_{2} \cdot t_{2}}+a_{4}+b_{4} \cdot e^{-c_{4} \cdot t_{4}} \\
& C_{M}\left(t_{Y 2}\right)=a_{1}+b_{1} \cdot e^{-c_{1} \cdot t_{1}}+a_{2}+b_{2} \cdot e^{-c_{2} \cdot t_{2}} \\
& +a_{3}+b_{3} \cdot e^{-c_{3} \cdot t_{3}}+a_{5}+b_{5} \cdot e^{-c_{5} \cdot t_{5}} \\
& C_{p m c 1}=\frac{U S L_{1}-L S L_{1}}{6 \sqrt{K_{1}\left[\left(U_{Y 1}-T_{1}\right)^{2}+\sigma_{Y 1}^{2}\right]+C_{M}\left(t_{Y 1}\right)}} \\
& C_{p m c 2}=\frac{U S L_{2}-L S L_{2}}{6 \sqrt{K_{2}\left[\left(U_{Y 2}-T_{2}\right)^{2}+\sigma_{Y 2}^{2}\right]+C_{M}\left(t_{Y 2}\right)}} \\
& \mathrm{C}_{\mathrm{pmcl}}=\frac{\mathrm{USL}_{1}-\mathrm{LSL}_{1}}{6 \sqrt{\left(\mathrm{U}_{\mathrm{Y} 1}-\mathrm{T}_{1}\right)^{2}+\sigma_{\mathrm{Y} 1}^{2}}} \\
& \mathrm{C}_{\mathrm{pmc} 2}=\frac{\mathrm{USL}_{2}-\mathrm{LSL}_{2}}{6 \sqrt{\left(\mathrm{U}_{\mathrm{Y} 2}-\mathrm{T}_{2}\right)^{2}+\sigma_{\mathrm{Y} 2}^{2}}}
\end{aligned}
$$




$$
\begin{aligned}
\mathrm{C}_{\mathrm{pmc}} & =\frac{\mathrm{C}_{\mathrm{pmc} 1}+\mathrm{C}_{\mathrm{pmc} 2}}{2} \\
T_{1}-S_{1}+t_{Y 1} & \leq U_{Y 1} \leq T_{1}+S_{1}-t_{Y 1} \\
T_{2}-S_{2}+t_{Y 2} & \leq U_{Y 2} \leq T_{2}+S_{2}-t_{Y 2} \\
4.9654 & \leq U_{1} \leq 5.0346 \\
8.4740 & \leq U_{2} \leq 8.5260 \\
3.9654 & \leq U_{3} \leq 4.0346 \\
8.3311 & \leq U_{4} \leq 8.3889 \\
17.6740 & \leq U_{5} \leq 17.7260 \\
0.03 & \leq t_{1} \leq 0.09 \\
0.02 & \leq t_{2} \leq 0.06 \\
0.03 & \leq t_{3} \leq 0.09 \\
0.04 & \leq t_{4} \leq 0.08 \\
0.03 & \leq t_{5} \leq 0.07
\end{aligned}
$$

\section{References}

Bare, M., \& Cox, J. J. (2008). Applying principles of mass customization to improve the empirical product development process. Journal of Intelligent Manufacturing, 19(5), 565-576.

Boyle, R. A. (1991). The Taguchi capability index. Journal of Quality Technology, 23, 17-26.

Carter, D. E., \& Baker, B. S. (1992). Concurrent engineering: The product development environment for the 1990s. New York: AddisonWesley.

Chan, L. K., Cheng, S. W., \& Spring, F. A. (1989). A new measurement of process capability: $\mathrm{C}_{\mathrm{pm}}$. Journal of Quality Technology, 20, 162 175.

Chase, K. W., Greenwood, W. H., Loosli, B. G., \& Haugland, L. F. (1990). Least cost tolerance allocation for mechanical assemblies with automated process selection. Manufacturing Review, 3(1), 4959.

Du, S., Lv, J., \& Xi, L. (2012). A robust approach for root causes identification in machining processes using hybrid learning algorithm and engineering knowledge. Journal of Intelligent Manufacturing, 23(5), 1833-1847.

Hussain, G., Lin, G., \& Hayat, N. (2011). Improving profile accuracy in SPIF process through statistical optimization of forming parameters. Journal of Mechanical Science and Technology, 25(1), 177-182.
Jeang, A. (1994). Tolerance design: Choosing optimal tolerance specification in the design machined parts. Quality and Reliability Engineering International, 10(1), 27-35.

Jeang, A. (1995). Economic tolerance design for quality. Quality and Reliability Engineering International, 11(2), 113-121.

Jeang, A. (2009). Optimal process capability analysis for process design. International Journal of Production Research, 48(4), 957989.

Jeang, A., \& Chang, C. L. (2002). Concurrent optimization of parameter tolerance design via computer simulation and statistical method. International Journal of Advanced Manufacturing Technology, 19(6), 432-441.

Jeang, A., \& Chung, C. P. (2009). Process capability analysis based on minimum production cost and quality loss. International Journal of Advanced Manufacturing Technology, 43(7), 710-719.

Kotz, S., \& Johnson, N. L. (1993). Process capability indices. London: Chapman \& Hall.

Kotz, S., \& Lovelace, C. R. (1998). Process capability indices in theory and practice. New York: Arnold, a member of the hodder headline group.

Lee, K. K., Park, C. K., \& Han, S. H. (2010). Robust design of railway vehicle suspension using a process capability index. Journal of Mechanical Science and Technology, 24, 215-218.

Marshall, B., \& Jordan, J. C. (2008). Applying principles of mass customization to improve the empirical product development process. Journal of Intelligent Manufacturing, 19(5), 565-576.

Michel, A., Elise, V., \& Meriem, D. (2010). Towards an association of product configuration with production planning. International Journal of Mass Customization, 3(4), 316-332.

Mohsen, S., Frédéric, N., \& Khaled, H.-H. (2010). Development of control mechanisms to support coherency of product model during cooperative design process. Journal of Intelligent Manufacturing, 21(4), 539-554.

Montgomery, D. C. (1991). Design and analysis of experiments. New York: Wiley.

Phadke, M. S. (1989). Quality engineering using robust design. Englewood Cliffs, NJ: Prentice Hall.

SAS Institute. (2001). SAS/STAT user's guide. Cary, NC: SAS Institute Inc.

Sibalija, T. V., \& Majstorovic, V. D. (2012). An integrated approach to optimise parameter design of multi-response processes based on Taguchi method and artificial intelligence. Journal of Intelligent Manufacturing, 23(5), 1511-1528.

Taguchi, G., \& Wu, Y. (1985). Introduction to off-line quality control. Japan: Central Japan Quality Control Association. 